\title{
Highly Luminescent Salts Containing Well-Shielded Lanthanide- Centered Complex Anions and Bulky Imidazolium Countercations
}

\author{
Si-Fu Tang, ${ }^{* \dagger}{ }^{\dagger}$ Chantal Lorbeer, ${ }^{\ddagger}$ Xinjiao Wang, ${ }^{\ddagger}$ Pushpal Ghosh, ${ }^{\ddagger}$, and Anja-Verena Mudring ${ }^{*}, \ldots, \|, \perp$ \\ ${ }^{\dagger}$ Key Laboratory of Biofuel, Chinese Academy of Sciences, Qingdao Institute of Bioenergy and Bioprocess Technology, 266101 \\ Qingdao, China \\ ${ }^{\ddagger}$ Anorganische Chemie III-Festkörperchemie und Materialien, Ruhr-Universität Bochum, 44801 Bochum, Germany \\ ${ }^{\S}$ School of Chemical Science and Technology, Department of Chemistry, Dr. H. S. Gour University (A Central University), Sagar, \\ 470003 Madhya Pradesh India \\ "Materials Science and Engineering, Iowa State University, Ames, Iowa 50014, United States \\ ${ }^{\perp}$ Critical Materials Institute, Ames Laboratory, Ames, Iowa 50011, United States
}

\section{Supporting Information}

ABSTRACT: Four salts containing imidazolium cations and europium(III)- or terbium(III)-centered complex anions have been successfully synthesized from an ethanol/ $\mathrm{H}_{2} \mathrm{O}$ solution. The single-crystal X-ray diffraction analyses reveal that these compounds have a common formula of $[\mathrm{R}]\left[\operatorname{Ln}(\mathrm{DETCAP})_{4}\right]$ $\left[\mathrm{R}=1\right.$-ethyl-3-methylimidazolium $\left(\mathrm{C}_{2} \mathrm{mim}\right), \mathrm{Ln}=\mathrm{Eu}(\mathbf{1})$ and $\mathrm{Tb}$ (2); R = 1-butyl-3-methylimidazolium ( $\left.\mathrm{C}_{4} \mathrm{mim}\right), \mathrm{Ln}=\mathrm{Eu}$ (3) and Tb (4); DETCAP = diethyl-2,2,2-trichloroacetylphosphoramidate], in which the lanthanide centers are chelated by four chelating pseudo- $\beta$-diketonate ligands (DETCAP) ${ }^{-}$,

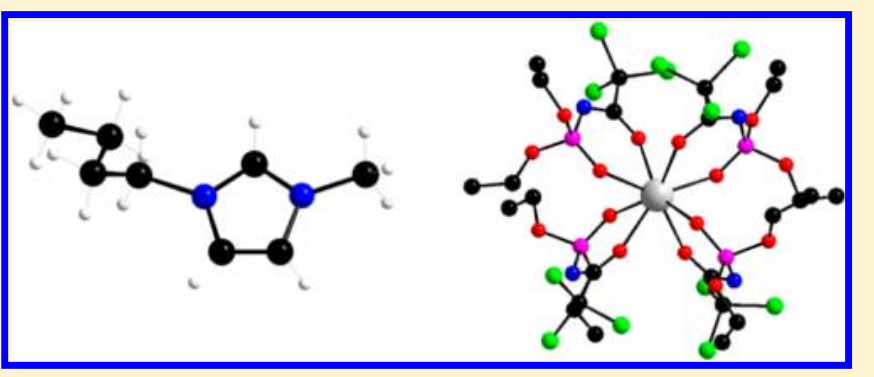
forming the respective complex anions. Their thermal behaviors and stabilities were also investigated to study the role of the length of the side chain in the cations. Fluorescence measurements at both room temperature and liquid-nitrogen temperature show that these materials show intense characteristic europium(III) or terbium(III) emissions and have long decay times. Their overall quantum yields were determined to be in the range of $30-49 \%$.

\section{INTRODUCTION}

Ionic liquids (ILs) have attracted great attention in the past decade in the fields of organic and inorganic synthesis, catalysis, extraction, electrolyte, etc. ${ }^{1}$ Most of time ILs have been studied as alternative solvents for conventional molecular solvents for their "green" and property-tunable character. ${ }^{2}$ With development, new applications including magnetism, ${ }^{3}$ luminescence, ${ }^{4}$ and liquid crystallization ${ }^{5}$ have been exploited for a new generation of ILs, which can be regarded as functional materials. As is known, traditional ILs usually are comprised of weakly coordinating anions. However, especially the anions are not as "innocent" as believed: some of them can coordinate or chelate metal ions and even form new ILs with cationic and anionic complex anions. As a result, new ILs with specific properties that are due to the incorporation of a metal ion can be realized and their properties tuned by a judicious combination of the chelating organic cations and/or anions and metal ions. ${ }^{6}$ An interesting field of application is the use of ILs as soft luminescent materials. ${ }^{7}$

Many (clean) ILs are transparent in the visible and near-IR spectral regions and are therefore very good optical solvents. ${ }^{8}$ Some researches indicated that the emission intensity of some lanthanide compounds could be significantly enhanced several orders of magnitude in the presence of ILs and some lanthanide complexes can be photochemically stabilized by some weakly coordinating imidazolium-based ILs. ${ }^{9}$ There are several ways to incorporate a lanthanide ion into an IL. ILs functionalized with coordinating groups such as carboxylic acid are able to dissolve lanthanide oxides and can directly be used to prepare luminescent lanthanide-doped ILs in which the luminescent components are cationic complexes. Unfortunately, these kinds of salts contain water, which quenches the useful emissions. ${ }^{10}$ In our previous studies, some various lanthanide-containing ILs were obtained by dissolving a lanthanide salt directly into an IL. The strong emissions of the obtained materials clearly indicated that ILs are promising media to study the luminescent properties of rare-earth cations in the liquid state because they generally quench the optical transition far less than conventional solvents. ${ }^{11}$ Homoleptic lanthanide-containing ILs, usually with a general composition of $[\text { cation }]_{x}\left[\operatorname{Ln}(\text { anion })_{3+x}\right]$ $(x=1-3)$, can also be obtained by the reaction of a lanthanide salt with an IL that shares the same anion. ${ }^{12}$ The most successful examples are $[\mathrm{R}]_{x}\left[\mathrm{Eu}\left(\mathrm{Tf}_{2} \mathrm{~N}\right)_{3+x}\right]\left[\mathrm{Tf}_{2} \mathrm{~N}=\right.$ bis(trifluoromethanesulfonyl)amide; $x=1$ for $\mathrm{R}=1$-propyl-1methylimidazolium $\left(\mathrm{C}_{3} \mathrm{mim}\right)$ and 1-butyl-1-methylimidazolium

Received: April 29, 2014

Published: August 14, 2014 
Table 1. Crystal and Refinement Data for Compounds 1-4

\begin{tabular}{|c|c|c|c|c|}
\hline & 1 & 2 & 3 & 4 \\
\hline empirical formula & $\mathrm{C}_{60} \mathrm{H}_{102} \mathrm{Cl}_{24} \mathrm{Eu}_{2} \mathrm{~N}_{12} \mathrm{O}_{32} \mathrm{P}_{8}$ & $\mathrm{C}_{60} \mathrm{H}_{102} \mathrm{Cl}_{24} \mathrm{~Tb}_{2} \mathrm{~N}_{12} \mathrm{O}_{32} \mathrm{P}_{8}$ & $\mathrm{C}_{64} \mathrm{H}_{110} \mathrm{Cl}_{24} \mathrm{Eu}_{2} \mathrm{~N}_{12} \mathrm{O}_{32} \mathrm{P}_{8}$ & $\mathrm{C}_{64} \mathrm{H}_{110} \mathrm{Cl}_{24} \mathrm{~Tb}_{2} \mathrm{~N}_{12} \mathrm{O}_{32} \mathrm{P}_{8}$ \\
\hline fw & 2906.02 & 2919.94 & 2962.12 & 2976.04 \\
\hline space group & $P \overline{1}$ & $P \overline{1}$ & $P \overline{1}$ & $P \overline{1}$ \\
\hline$a(\AA)$ & $14.9952(3)$ & $14.9532(4)$ & $13.1772(3)$ & $13.1929(5)$ \\
\hline$b(\AA)$ & $18.6722(3)$ & $18.6732(6)$ & $22.2635(5)$ & $22.2461(7)$ \\
\hline$c(\AA)$ & $23.2983(6)$ & $23.2428(11)$ & $22.3029(5)$ & $22.2683(8)$ \\
\hline$\alpha(\mathrm{deg})$ & $106.8200(10)$ & $106.830(2)$ & $79.4160(10)$ & $79.458(2)$ \\
\hline$\beta(\operatorname{deg})$ & $100.5020(10)$ & $100.549(2)$ & $86.0050(10)$ & $85.891(2)$ \\
\hline$\gamma(\operatorname{deg})$ & $100.4160(10)$ & $100.2530(10)$ & $73.8050(10)$ & $73.728(2)$ \\
\hline$V\left(\AA^{3}\right)$ & $5947.7(2)$ & $5920.1(4)$ & $6175.3(2)$ & $6166.4(4)$ \\
\hline$Z$ & 2 & 2 & 2 & 2 \\
\hline$D_{\text {calcd }}\left(\mathrm{g} / \mathrm{cm}^{3}\right)$ & 1.623 & 1.638 & 1.593 & 1.603 \\
\hline abs coeff $\left(\mathrm{mm}^{-1}\right)$ & 1.761 & 1.905 & 1.698 & 1.830 \\
\hline reflns & 59454 & 64023 & 79816 & 48330 \\
\hline reflns $/ R_{\text {int }}$ & $20823 / 0.0341$ & $20752 / 0.0383$ & $27895 / 0.0461$ & $21575 / 0.0340$ \\
\hline GOF on $F^{2}$ & 1.023 & 1.017 & 1.009 & 1.055 \\
\hline $\mathrm{R} 1, \mathrm{wR} 2[I>2 \sigma(I)]$ & $0.0484,0.1176$ & $0.0467,0.1164$ & $0.0562,0.1370$ & $0.0503,0.1318$ \\
\hline $\mathrm{R} 1$, wR2 (all data) & $0.0699,0.1388$ & $0.0635,0.1303$ & $0.1160,0.1682$ & $0.0855,0.1460$ \\
\hline
\end{tabular}

$\left(\mathrm{C}_{4} \mathrm{mim}\right) ; x=2$ for $\mathrm{R}=1$-butyl-1-methylpyrrolidinium $\left.\left(\mathrm{C}_{4} \mathrm{mpyr}\right)\right] .{ }^{13}$ In these salts, the europium ions are wrapped by four or five fluorinated sulfonylamide ligands and, importantly, there are no water molecules in them. As expected, these europium-incorporated salts not only exhibit very strong characteristic red emissions but also have very long decay times. These successes suggested that lanthanide-containing ILs are very promising luminescent materials.

Early syntheses of these luminescent materials required rigorous synthesis conditions, including anhydrous starting materials, a drybox, inert gas protection, dynamic vacuum, etc. In the course of our and others' studies of the use of $\beta$ diketone-type ligands for the preparation of luminescent materials, ${ }^{9,14}$ we have found that anhydrous salts can be readily synthesized from aqueous solutions of lanthanide salts, precursor ILs, and $\beta$-diketone ligands. It is well-known that $\beta$-diketone-type ligands have the ability to chelate with lanthanide ions, forming stable coordination compounds. At the same time, their adsorption coefficients are very high, and are therefore very good sensitizers for optical materials for consideration of the antenna effect. ${ }^{15}$

Carbacylamidophosphates and their derivatives, which have been extensively studied, ${ }^{16}$ are one type of $\mathrm{O}, \mathrm{O}^{\prime}$-chelators, which should be good sensitizers because of their generally quite high adsorption coefficient. At the same time, it is possible to tune the ligand electronic structure and efficiently improve the luminescence of the lanthanide ion by substitution using the push-pull structural character. ${ }^{17}$ Additionally, these kinds of ligands contain two ester groups, which can form a shell covering the lanthanide centers and prevent them from attacking by high-energy oscillators. Upon a survey of the literature, we find that up until now no attempt has been made to the study of ILs or soft materials from these kinds of ligands. Therefore, we decide to develop new luminescent salts from diethyl-2,2,2-trichloroacetylphosphoramidate (DETCAP). Herein, we report on the syntheses, structures, thermal behaviors, and photoluminescent properties of four lanthanide-incorporated salts, namely, $[\mathrm{R}]\left[\mathrm{Ln}(\mathrm{DETCAP})_{4}\right][\mathrm{R}=1$ ethyl-3-methylimidazolium $\left(\mathrm{C}_{2} \mathrm{mim}\right), \mathrm{Ln}=\mathrm{Eu}(\mathbf{1})$ and $\mathrm{Tb}(2)$; $\mathrm{R}=1$-butyl-3-methylimidazolium $\left(\mathrm{C}_{4} \mathrm{mim}\right), \mathrm{Ln}=\mathrm{Eu}(3)$ and $\mathrm{Tb}(4)]$.

\section{EXPERIMENTAL DETAILS}

Materials and Methods. $\mathrm{LnCl}_{3} \cdot 6 \mathrm{H}_{2} \mathrm{O}(\mathrm{Ln}=\mathrm{Eu}$ and $\mathrm{Tb}$; Smart Elements), 1-ethyl-3-methylimidazolium chloride $\left[\left(\mathrm{C}_{2} \mathrm{mim}\right) \mathrm{Cl}\right]$ and 1-butyl-3-methylimidazolium chloride $\left[\left(\mathrm{C}_{4} \mathrm{mim}\right) \mathrm{Cl}\right]$ (Iolitec), and all solvents were obtained from commercial sources and used as received. Elemental analyses were performed on a Vario EL III elemental analyzer. IR spectra were recorded on a Nicolet 6700 FTIR spectrometer as $\mathrm{KBr}$ pellets in the range of $4000-400 \mathrm{~cm}^{-1}$. Solution ${ }^{1} \mathrm{H} \mathrm{NMR}$ spectra were recorded on a Bruker AVANCE-III NMR spectrometer $(600 \mathrm{MHz})$. Thermogravimetric analyses (TGA) were carried out on a NETZSCH STA 449C unit at a heating rate of $10{ }^{\circ} \mathrm{C} / \mathrm{min}$ under a nitrogen atmosphere. Phase transition temperatures were determined with a differential scanning calorimeter (NETZSCH DSC 240 F1). Measurements were carried out at a heating rate of $5{ }^{\circ} \mathrm{C} / \mathrm{min}$ in sealed aluminum pans with an argon flow rate of $20 \mathrm{~mL} / \mathrm{min}$. The reference sample was an empty aluminum container. Powder X-ray diffraction (XRD) patterns of the title compounds 1-4 were obtained on a Bruker D8 Advance diffractometer using $\mathrm{Cu} \mathrm{K} \alpha$ radiation. The results are presented in Figures S1-S4 in the Supporting Information and compared with the simulated patterns from the single-crystal structural analyses. Good agreement confirms that the crystal structures are truly representative of the bulk materials.

Excitation and emission spectra were recorded at room temperature (RT) and liquid-nitrogen temperature (77 K) using a Fluorolog 3 (Jobin Yvon Gmbh, München, Germany) with a continuous xenon lamp for steady-state spectra and a pulsed xenon lamp for time-dependent spectra as the excitation sources and a photomultiplier tube for detection. Bulk samples were sealed in silica tubes. Electronic transitions were assigned according to the energy level diagrams of trivalent rare-earth ions. ${ }^{18}$ The absolute quantum yields of compounds $1-4$ were measured using the integrating sphere approach (Jobin-Yvon) through the following expression: $\Phi=E_{\mathrm{c}} /\left(L_{\mathrm{a}}-L_{\mathrm{c}}\right)=E_{\mathrm{c}} / L_{\mathrm{a}} \alpha$ in which $E_{\mathrm{c}}$ is the integrated emission spectrum of the sample, $\alpha$ is sample absorbance, which is found by measuring the integrated excitation profiles, $L_{\mathrm{a}}$ is the "blank" absorption, and $L_{\mathrm{c}}$ is the sample absorption at the excitation wavelength. 
Crystal Structure Determination of 1-4. Intensity data collections of 1-4 were carried out on a Bruker Smart APEX2 CCD single-crystal X-ray diffractometer (Mo K $\alpha$ radiation, $\lambda=$ $0.71071 \AA$ ) at RT. SAINT was used for integration of the intensity of reflections and scaling. ${ }^{19}$ Absorption corrections were carried out with the program SADABS. ${ }^{20}$ Crystal structures were solved by direct methods using SHELXS. ${ }^{21}$ Subsequent difference Fourier analyses and least-squares refinement with SHELXL- $97^{22}$ allowed for the location of the atom positions. In the final step of the crystal structure refinement, hydrogen atoms of idealized $-\mathrm{CH}_{2}$ and $-\mathrm{CH}_{3}$ groups were added and treated with the riding atom mode, and their isotropic displacement factors were chosen as 1.2 and 1.5 times the preceding carbon atom, respectively. Two $-\mathrm{CCl}_{3}$ groups in compounds $\mathbf{1 - 4}$ are disordered over two positions; therefore, they are refined isotropically because of the high displacement parameters. The high or low $U_{\text {eq }}$ found in compounds 3 and 4 should be caused by RT data collection. Crystallographic details for compounds $\mathbf{1 - 4}$ are summarized in Table 1. Data for the crystal structures of compounds 1-4 have been deposited at the Cambridge Crystallographic Data Centre (CCDC 970447-970450); these data are obtainable free of charge via the Internet at ww.ccdc.cam.ac.uk/conts/retrieving. html.

Synthesis of Diethyl-2,2,2-trichloroacetylphosphoramidate (DETCAP). DETCAP was synthesized from 2,2,2trichloroacetamide and diethylphosphorochloridate under an atmosphere of argon (see Scheme 1). A total of $4.872 \mathrm{~g}$ (30

Scheme 1. Synthesis Procedure of Ligand HDETCAP

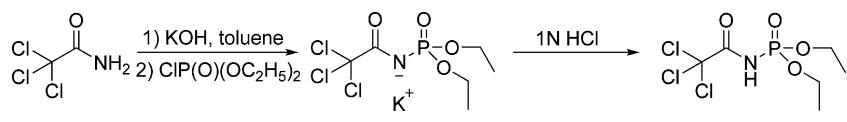

$\mathrm{mmol}$ ) of 2,2,2-trichloroacetamide was dissolved in $200 \mathrm{~mL}$ of dry toluene and mixed with $600 \mathrm{mmol}$ of $\mathrm{KOH}$. The mixture was stirred at RT for $2 \mathrm{~h}$ and then cooled to $0{ }^{\circ} \mathrm{C}$. An equivalent molar amount of diethyl chlorophosphate $(4.56 \mathrm{~mL})$ was added dropwise slowly under vigorous stirring. The mixture was stirred at this temperature for a further $3 \mathrm{~h}$ and left overnight at RT. Then $500 \mathrm{~mL}$ of deionized water was added and stirred for $30 \mathrm{~min}$. The water phase was separated and treated with $1 \mathrm{~N} \mathrm{HCl}$ to reach a $\mathrm{pH}$ value of 4-5. After that, it was extracted three times with toluene and dried with anhydrous $\mathrm{MgSO}_{4}$. A pure product (5.01 g, yield: $56 \%$ ) was then obtained after removal of the solvent and crystallization from dichloromethane. ${ }^{1} \mathrm{H}$ NMR (DMSO- $\left.d^{6}\right): \delta 10.84(\mathrm{~s}, 1 \mathrm{H}$, $-\mathrm{NH}-), 4.16-4.08\left(\mathrm{~m}, 4 \mathrm{H},-\mathrm{CH}_{2}-\right), 1.28-1.26(\mathrm{t}, 6 \mathrm{H}$, $\left.-\mathrm{CH}_{3}\right)$. IR $\left(\mathrm{cm}^{-1}\right): 3460.7(\mathrm{~b}, \mathrm{~m}), 3072.7(\mathrm{~s}), 2993.9(\mathrm{~m})$, 2884.9 (s), 2704.6 (w), 1743.8 (vs), 1624.8 (w), 1462.8 (vs), $1393.8(\mathrm{~m}), 1369.9(\mathrm{w}), 1264.6(\mathrm{vs}), 1211.6(\mathrm{~s}), 1166.9(\mathrm{~m})$, 1030.7 (vs), 991.2 (s), 964.3 (s), 908.0 (s), 831.2 (vs), 751.7 (w), 674.8 (vs), 532.0 (s).

Synthesis of Compounds 1-4. $\left[\mathrm{C}_{2} \mathrm{mim}\right] \mathrm{Cl}(0.1466 \mathrm{~g}, 1.0$ $\mathrm{mmol})$ or $\left[\mathrm{C}_{4} \mathrm{mim}\right] \mathrm{Cl}(0.1747 \mathrm{~g}, 1.0 \mathrm{mmol})$, HDETCAP $(0.8322 \mathrm{~g}, 4 \mathrm{mmol})$, and $4 \mathrm{~mL}(4 \mathrm{mmol})$ of a $1 \mathrm{M} \mathrm{NaOH}$ aqueous solution were added to $6 \mathrm{~mL}$ of ethanol in a $25 \mathrm{~mL}$ beaker. The reaction mixture was stirred and heated to $50{ }^{\circ} \mathrm{C}$. When a clear solution was formed, an aqueous solution of lanthanide(III) chloride ( $1 \mathrm{mmol}$; Eu, $0.3664 \mathrm{~g}$; Tb, $0.3734 \mathrm{~g}$ ) in $2 \mathrm{~mL}$ of water was added dropwise. The reaction solution was stirred for another $30 \mathrm{~min}$ at $50{ }^{\circ} \mathrm{C}$ and then cooled to RT.
A white precipitate formed, collected by filtration, and carefully washed with ice-cooled water. Suitable single crystals for X-ray structural analyses were obtained by recrystallizing from ethanol.

Elem anal. Calcd for $\left[\mathrm{C}_{2} \mathrm{mim}\right]\left[\mathrm{Eu}(\mathrm{DETCAP})_{4}\right]$ (1; $\left.\mathrm{C}_{60} \mathrm{H}_{102} \mathrm{Cl}_{24} \mathrm{Eu}_{2} \mathrm{~N}_{12} \mathrm{O}_{32} \mathrm{P}_{8}, 2906.1132\right): \mathrm{C}, 24.80 ; \mathrm{H}, 3.54 ; \mathrm{N}$, 5.78. Found: C, 24.86; H, 3.64; N, 5.83. Elem anal. Calcd for $\left[\mathrm{C}_{2} \mathrm{mim}\right]\left[\mathrm{Tb}(\mathrm{DETCAP})_{4}\right] \quad\left(\mathbf{2} ; \mathrm{C}_{60} \mathrm{H}_{102} \mathrm{Cl}_{24} \mathrm{~Tb}_{2} \mathrm{~N}_{12} \mathrm{O}_{32} \mathrm{P}_{8}\right.$, 2920.0332): C, 24.68; H, 3.52; N, 5.76. Found: C, 24.60; H, 3.44; N, 5.70. Elem anal. Calcd for $\left[\mathrm{C}_{4} \mathrm{mim}\right]\left[\mathrm{Eu}(\mathrm{DETCAP})_{4}\right]$ (3; $\left.\mathrm{C}_{64} \mathrm{H}_{110} \mathrm{Cl}_{24} \mathrm{Eu}_{2} \mathrm{~N}_{12} \mathrm{O}_{32} \mathrm{P}_{8}, 2962.12\right): \mathrm{C}, 25.95 ; \mathrm{H}, 3.74 ; \mathrm{N}$, 5.67. Found: C, 26.01; H, 3.82; N, 5.61. Elem anal. Calcd for $\left[\mathrm{C}_{4} \mathrm{mim}\right]\left[\mathrm{Tb}(\mathrm{DETCAP})_{4}\right] \quad\left(4 ; \mathrm{C}_{64} \mathrm{H}_{110} \mathrm{Cl}_{24} \mathrm{~Tb}_{2} \mathrm{~N}_{12} \mathrm{O}_{32} \mathrm{P}_{8}\right.$, 2976.1407): C, 25.83; H, 3.73; N, 5.65. Found: C, 25.77; H, $3.82 ; \mathrm{N}, 5.60$.

\section{RESULTS AND DISCUSSION}

Structural Description of Compounds 1-4. All four compounds crystallize in the triclinic $P \overline{1}$ space group with two molecules in each unit cell. They have very similar structures, which have two $\left[\mathrm{C}_{n} \mathrm{mim}\right]^{+}$dialkylimidazolium cations and two $\left[\operatorname{Ln}(\mathrm{DETCAP})_{4}\right]^{-}$complex anions in each asymmetric unit, corresponding to a formula of $\left[\mathrm{C}_{n} \mathrm{mim}\right]\left[\operatorname{Ln}(\mathrm{DETCAP})_{4}\right](n=$ 2, 4). Compounds 1 and 2 and compounds 3 and 4 are isostructural. The $\left[\operatorname{Ln}(\mathrm{DETCAP})_{4}\right]^{-}$complex anion is formed by the chelation of four DETCAP anions to one lanthanide center with a distorted square-antiprismatic coordination geometry. The $\mathrm{Eu}-\mathrm{O}$ distances are found in the ranges of 2.356(4)-2.457(4) $\AA$ for 1 and 2.349(9)-2.456(10) $\AA$ for 3, and the $\mathrm{Tb}-\mathrm{O}$ bond lengths are in the ranges of $2.326(4)-$ 2.439(4) Å for 2 and 2.313-2.438 Å for 4 (see Table 2); both are in the normal ranges compared with other reported lanthanide $\beta$-diketonates. ${ }^{14,16 \mathrm{~d}, 23}$ The neighboring two [Ln$\left.(\mathrm{DETCAP})_{4}\right]^{-}$complex anions are linked by one $\left[\mathrm{C}_{n} \mathrm{mim}\right]^{+}$ dialkylimidazolium cation via $\mathrm{C}-\mathrm{H} \cdots \mathrm{O}$ interactions (see Figures 1a and 2a and Table S1 in the Supporting Information) between the three acidic hydrogen atoms of the imidazolium cation and the oxygen atoms of the DETCAP anion, resulting in the formation of a one-dimensional (1D) infinite chain along the (110) direction for $\mathbf{1}$ and $\mathbf{2}$ and the $b$ axis for $\mathbf{3}$ and $\mathbf{4}$. These 1D chains assemble into a three-dimensional (3D) supramolecular structure via van der Waals interactions (see Figures $1 b$ and $2 b$ ).

Thermal Behavior Investigation. The thermal properties of compounds 1-4 were examined using differential scanning calorimetry (DSC) on powder samples, and the DSC thermograms are shown in Figure 3. As expected, compounds 1 and 2 and compounds 3 and 4 have very similar thermal behaviors. For 1 and 2, there are three distinct phases on both the heating and cooling traces in the temperature range of 20$180{ }^{\circ} \mathrm{C}$ (see Figure 3a,b). According to our experience, the two endothermic $\left(128.8\right.$ and $158.8^{\circ} \mathrm{C}$ for $1 ; 132.5$ and $151.0^{\circ} \mathrm{C}$ for 2) and exothermic $\left(83.7\right.$ and $134.7^{\circ} \mathrm{C}$ for $1 ; 70.9$ and $128.6^{\circ} \mathrm{C}$ for 2) peaks do not suggest that compounds 1 and 2 have liquid-crystal phases but normal solid-to-solid transition phases that are probably caused by the rotation of the organic cations. ${ }^{14}$ The thermal behaviors of 3 and $\mathbf{4}$ are a little different from those of $\mathbf{1}$ and $\mathbf{2}$ (see Figure $3 \mathrm{c}, \mathrm{d}$ ). There are also two endothermic peaks (91.1 and $128.3^{\circ} \mathrm{C}$ for 3 ; 86.4 and $127.2^{\circ} \mathrm{C}$ for 4) on the heating traces but only one exothermic peak $\left(114.7{ }^{\circ} \mathrm{C}\right.$ for $3 ; 112.7^{\circ} \mathrm{C}$ for 4$)$ on the cooling traces. This kind of difference could be ascribed to the larger size of the $\left(\mathrm{C}_{4} \mathrm{mim}\right)^{+}$cation, which makes it more difficult to rotate than 
Table 2. Selected Bond Lengths for Compounds 1-4

\begin{tabular}{|c|c|c|c|}
\hline \multicolumn{4}{|c|}{1} \\
\hline $\mathrm{Eu} 1-\mathrm{O} 2$ & $2.356(4)$ & $\mathrm{Eu} 2-\mathrm{O} 26$ & $2.359(4)$ \\
\hline Eu1-O6 & $2.360(4)$ & $\mathrm{Eu} 2-\mathrm{O} 34$ & $2.362(4)$ \\
\hline $\mathrm{Eu} 1-\mathrm{O} 10$ & $2.363(4)$ & $\mathrm{Eu} 2-\mathrm{O} 30$ & $2.384(4)$ \\
\hline Eu1-O14 & $2.379(4)$ & $\mathrm{Eu} 2-\mathrm{O} 22$ & $2.386(4)$ \\
\hline Eu1-O5 & $2.438(4)$ & $\mathrm{Eu} 2-\mathrm{O} 33$ & $2.416(4)$ \\
\hline $\mathrm{Eu} 1-\mathrm{O} 13$ & $2.445(4)$ & $\mathrm{Eu} 2-\mathrm{O} 21$ & $2.424(4)$ \\
\hline Eu1-O9 & $2.449(4)$ & $\mathrm{Eu} 2-\mathrm{O} 29$ & $2.437(4)$ \\
\hline Eu1-O1 & $2.457(4)$ & $\mathrm{Eu} 2-\mathrm{O} 25$ & $2.437(4)$ \\
\hline \multicolumn{4}{|c|}{2} \\
\hline $\mathrm{Tb} 1-\mathrm{O} 6$ & $2.326(4)$ & $\mathrm{Tb} 2-\mathrm{O} 34$ & $2.331(4)$ \\
\hline $\mathrm{Tb} 1-\mathrm{O} 2$ & $2.327(4)$ & $\mathrm{Tb} 2-\mathrm{O} 26$ & $2.334(4)$ \\
\hline $\mathrm{Tb} 1-\mathrm{O} 10$ & $2.335(4)$ & $\mathrm{Tb} 2-\mathrm{O} 30$ & $2.356(4)$ \\
\hline $\mathrm{Tb} 1-\mathrm{O} 14$ & $2.348(4)$ & $\mathrm{Tb} 2-\mathrm{O} 22$ & $2.358(4)$ \\
\hline $\mathrm{Tb} 1-\mathrm{O} 5$ & $2.418(4)$ & $\mathrm{Tb} 2-\mathrm{O} 33$ & $2.391(4)$ \\
\hline $\mathrm{Tb} 1-\mathrm{O} 13$ & $2.427(4)$ & $\mathrm{Tb} 2-\mathrm{O} 21$ & $2.401(4)$ \\
\hline Tb1-O9 & $2.431(4)$ & $\mathrm{Tb} 2-\mathrm{O} 25$ & $2.412(4)$ \\
\hline $\mathrm{Tb} 1-\mathrm{O} 1$ & $2.439(4)$ & $\mathrm{Tb} 2-\mathrm{O} 29$ & $2.416(4)$ \\
\hline \multicolumn{4}{|c|}{3} \\
\hline Eu1-O6 & $2.347(13)$ & $\mathrm{Eu} 2-\mathrm{O} 30$ & $2.358(15)$ \\
\hline Eul-O10 & $2.366(14)$ & $\mathrm{Eu} 2-\mathrm{O} 22$ & $2.363(16)$ \\
\hline $\mathrm{Eu} 1-\mathrm{O} 2$ & $2.368(14)$ & $\mathrm{Eu} 2-\mathrm{O} 26$ & $2.369(13)$ \\
\hline Eu1-O14 & $2.385(13)$ & Eu2-O18 & $2.372(13)$ \\
\hline $\mathrm{Eu} 1-\mathrm{O} 13$ & $2.428(13)$ & $\mathrm{Eu} 2-\mathrm{O} 17$ & $2.433(14)$ \\
\hline Eu1-O1 & $2.432(16)$ & $\mathrm{Eu} 2-\mathrm{O} 21$ & $2.440(16)$ \\
\hline $\mathrm{Eu} 1-\mathrm{O} 5$ & $2.448(14)$ & $\mathrm{Eu} 2-\mathrm{O} 29$ & $2.441(14)$ \\
\hline Eu1-O9 & $2.451(15)$ & $\mathrm{Eu} 2-\mathrm{O} 25$ & $2.459(14)$ \\
\hline \multicolumn{4}{|c|}{4} \\
\hline $\mathrm{Tb} 1-\mathrm{O} 6$ & $2.313(4)$ & $\mathrm{Tb} 2-\mathrm{O} 30$ & $2.327(5)$ \\
\hline $\mathrm{Tb} 1-\mathrm{O} 10$ & $2.339(4)$ & $\mathrm{Tb} 2-\mathrm{O} 22$ & $2.331(5)$ \\
\hline $\mathrm{Tb} 1-\mathrm{O} 2$ & $2.346(4)$ & $\mathrm{Tb} 2-\mathrm{O} 18$ & $2.346(4)$ \\
\hline $\mathrm{Tb} 1-\mathrm{O} 14$ & $2.348(4)$ & $\mathrm{Tb} 2-\mathrm{O} 26$ & $2.356(4)$ \\
\hline $\mathrm{Tb} 1-\mathrm{O} 13$ & $2.413(4)$ & $\mathrm{Tb} 2-\mathrm{O} 29$ & $2.418(5)$ \\
\hline $\mathrm{Tb} 1-\mathrm{O} 1$ & $2.414(5)$ & $\mathrm{Tb} 2-\mathrm{O} 17$ & $2.419(4)$ \\
\hline Tb1-O9 & $2.424(5)$ & $\mathrm{Tb} 2-\mathrm{O} 21$ & $2.421(4)$ \\
\hline $\mathrm{Tb} 1-\mathrm{O} 5$ & $2.438(4)$ & $\mathrm{Tb} 2-\mathrm{O} 25$ & $2.435(5)$ \\
\hline
\end{tabular}

$\left(\mathrm{C}_{2} \mathrm{mim}\right)^{+}$with the changing of temperature. The melting points of compounds $\mathbf{1}$ and $\mathbf{2}$ are higher than those of $\mathbf{3}$ and $\mathbf{4}$. This is easy to understand because a bulky ion usually leads to lower melting points. The melting points of the four salts are all above $120{ }^{\circ} \mathrm{C}$ and are comparable with those of other $\beta$ diketonate-based salts. ${ }^{14}$

XRD, IR, and TGA Studies. The powder XRD patterns of the title compounds $\mathbf{1 - 4}$ are shown in the Supporting Information (Figures S1-S4). Good agreements between the respective experimental and simulated patterns from the singlecrystal structural data suggest good purity of the as-synthesized samples.

The neutral ligand HDETCAP bears a close resemblance to $\beta$-diketones, which show amide-imidole tautomerism. Upon coordination, the proton on the imine group is removed, giving rise to $\pi$ conjugation of the skeleton $\mathrm{O}=\mathrm{C}-\mathrm{N}-\mathrm{P}=\mathrm{O}$ and leading to elongation of the $\mathrm{C}=\mathrm{O}$ and $\mathrm{P}=\mathrm{O}$ bonds and contraction of the $\mathrm{C}-\mathrm{N}$ and $\mathrm{P}-\mathrm{N}$ bonds. ${ }^{24}$ For the IR band of the neutral chelate ligand (HDETCAP), the $\nu(\mathrm{N}-\mathrm{H})$ vibration lies around $3073 \mathrm{~cm}^{-1}$ (Table 3 ). This band is absent in the IR spectra of compounds $1-4$, indicating deprotonation of the chelate ligands and their coordination to the lanthanide ions. The characteristic vibration of the carbonyl group, which appears around $1744 \mathrm{~cm}^{-1}$ in the IR spectrum of DETCAP,

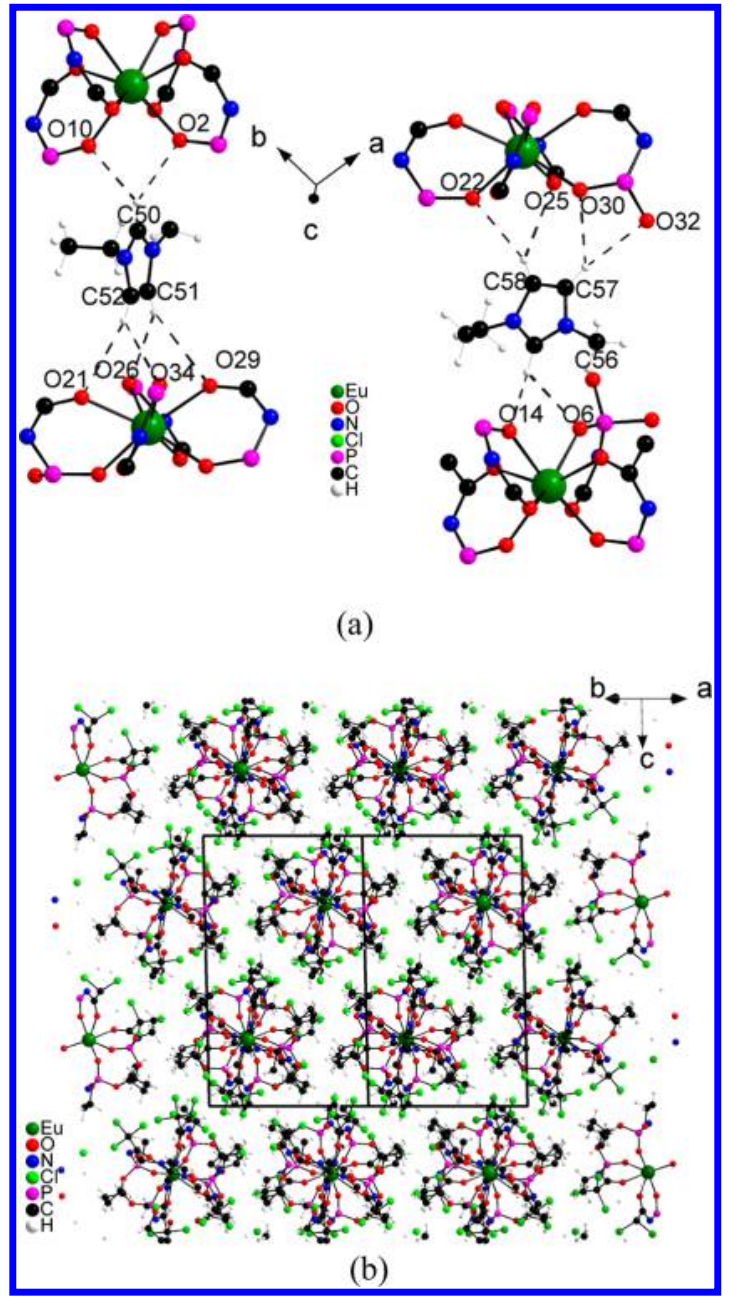

Figure 1. $\mathrm{C}-\mathrm{H} \cdots \mathrm{O}$ interactions (a) and $3 \mathrm{D}$ packing diagram of compound 1 along the (110) direction (b). In part a, the $-\mathrm{CCl}_{3}$ and $-\mathrm{OCH}_{2} \mathrm{CH}_{3}$ groups are omitted for clarity.

shifts to $1618 \mathrm{~cm}^{-1}$ in compounds $1-4$ because of delocalization of the $\mathrm{p}$ electron density in the chelate frame upon coordination. The IR spectra of the ligand and $\mathbf{1 - 4}$ reveal that the characteristic vibrations of the $-\mathrm{PO}_{3}$ groups appear in the ranges of $1265-1260 \mathrm{~cm}^{-1}$ for $\mathrm{P}=\mathrm{O}$ stretching, 1031$1037 \mathrm{~cm}^{-1}$ for asymmetric $\mathrm{P}-\mathrm{O}$ stretching, and $964-971 \mathrm{~cm}^{-1}$ for symmetric stretching vibrations, respectively. The lowfrequency shift of the $\nu(\mathrm{P}=\mathrm{O})$ bands in the spectra of the lanthanide-containing compounds provides further evidence of the coordination of the phosphoryl gorup to the lanthanide centers.

The thermal stabilities of compounds $\mathbf{1 - 4}$ were examined using TGA in the temperature range of $30-800{ }^{\circ} \mathrm{C}$, and the results are plotted in Figure 4. From the TGA traces, it is obvious that they have very similar weight loss trends that occur only in one step. No obvious weight loss before $180{ }^{\circ} \mathrm{C}$ can be observed for $\mathbf{1}$ and 2, whereas $\mathbf{3}$ and $\mathbf{4}$ start to lose weight from $160{ }^{\circ} \mathrm{C}$, suggesting better stability of 1 and 2 . Upon further heating, they start to decompose abruptly until $700{ }^{\circ} \mathrm{C}$ to reach a constant weight, at which temperature weight losses of $63.3 \%$ for $1,62.8 \%$ for $2,65.9 \%$ for 3 , and $64.8 \%$ for 4 were observed. Compared with other metal-containing ILs or soft materials, the stabilities of these four salts are moderate, and this could be ascribed to the moderate stability of the DETCAP ligand. 


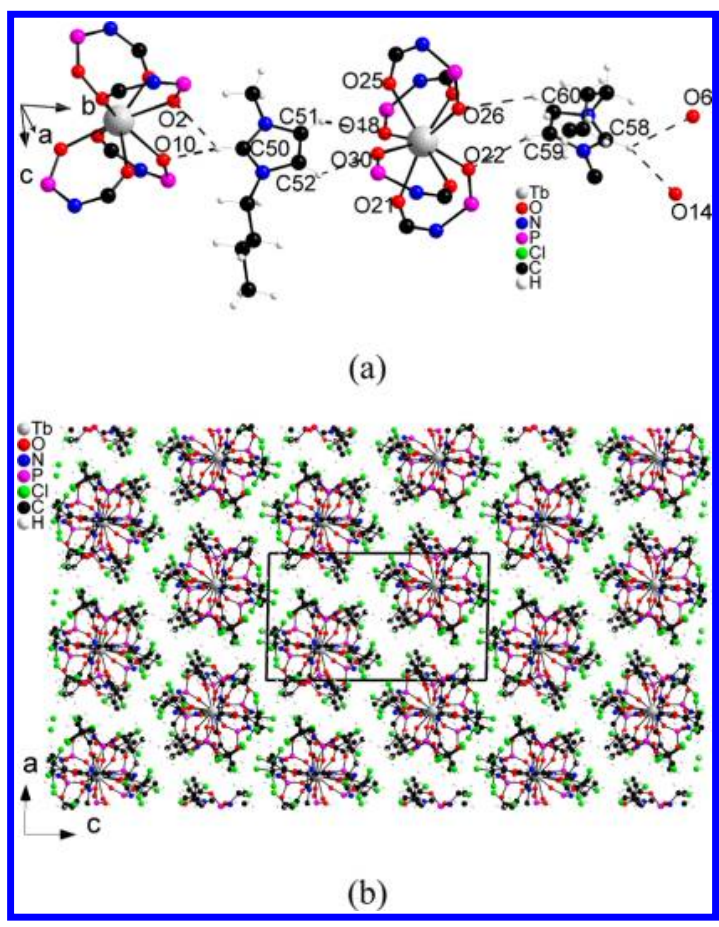

Figure 2. $\mathrm{C}-\mathrm{H} \cdots \mathrm{O}$ interactions (a) and $3 \mathrm{D}$ packing diagram of compound 4 along the $b$ direction (b). In part a, the $-\mathrm{CCl}_{3}$ and $-\mathrm{OCH}_{2} \mathrm{CH}_{3}$ groups are omitted for clarity.

Photoluminescent Properties of Compounds 1-4. The excitation and emission spectra of compounds 1-4 were recorded at both RT and liquid-nitrogen temperature (77 K; see Figures 5-8). As expected, both the europium- and terbium-containing salts are highly luminescent and display their respective characteristic transitions in the corresponding regions.

For compounds 1 and 3 , a series of intense lines corresponding to discrete $\mathrm{f}-\mathrm{f}$ transitions at $361,366\left({ }^{7} \mathrm{~F}_{0} \rightarrow\right.$ $\left.{ }^{5} \mathrm{D}_{4}\right), 373,375\left({ }^{7} \mathrm{~F}_{0 / 1} \rightarrow{ }^{5} \mathrm{G}_{\mathrm{J}}\right), 381,384\left({ }^{7} \mathrm{~F}_{0 / 1} \rightarrow{ }^{5} \mathrm{~L}_{7},{ }^{5} \mathrm{G}_{\mathrm{J}}\right), 393$, $395\left({ }^{7} \mathrm{~F}_{0} \rightarrow{ }^{5} \mathrm{~L}_{6}\right), 416\left({ }^{7} \mathrm{~F}_{0} \rightarrow{ }^{5} \mathrm{D}_{3}\right), 464\left({ }^{7} \mathrm{~F}_{0} \rightarrow{ }^{5} \mathrm{D}_{2}\right), 525\left({ }^{7} \mathrm{~F}_{0}\right.$ $\left.\rightarrow{ }^{5} \mathrm{D}_{1}\right)$, and $535 \mathrm{~nm}\left({ }^{7} \mathrm{~F}_{1} \rightarrow{ }^{5} \mathrm{D}_{1}\right)$ can be detected by monitoring at the ${ }^{5} \mathrm{D}_{0} \rightarrow{ }^{7} \mathrm{~F}_{2}$ transition $\left(\lambda_{\mathrm{em}}=612 \mathrm{~nm}\right)$ at either RT or liquid-nitrogen temperature.

The emission spectra of compounds $\mathbf{1}$ and $\mathbf{3}$ are very similar under excitation into the band corresponding to the ${ }^{7} \mathrm{~F}_{0} \rightarrow{ }^{5} \mathrm{~L}_{6}$ transition of the europium(III) ion $\left(\lambda_{\mathrm{ex}}=393 \mathrm{~nm}\right)$ at RT and liquid-nitrogen temperature (see Figures 5 and 6), indicating a similar coordination environment. A series of sharp lines, which can be attributed to the transitions between the first excited nondegenerate ${ }^{5} \mathrm{D}_{0}$ and ${ }^{7} \mathrm{~F}_{J}(J=0-4)$ levels of the fundamental europium(III) septet $\left[579\left({ }^{5} \mathrm{D}_{0} \rightarrow{ }^{7} \mathrm{~F}_{0}\right), 593\left({ }^{5} \mathrm{D}_{0} \rightarrow{ }^{7} \mathrm{~F}_{1}\right), 612\right.$, 613, $616\left({ }^{5} \mathrm{D}_{0} \rightarrow{ }^{7} \mathrm{~F}_{2}\right), 650\left({ }^{5} \mathrm{D}_{0} \rightarrow{ }^{7} \mathrm{~F}_{3}\right)$, and $697 \mathrm{~nm}\left({ }^{5} \mathrm{D}_{0} \rightarrow\right.$ $\left.\left.{ }^{7} \mathrm{~F}_{4}\right)\right]$, can be observed. The spectra are dominated by the hypersensitive transition ${ }^{5} \mathrm{D}_{0} \rightarrow{ }^{7} \mathrm{~F}_{2}$ band with a maximum around $612 \mathrm{~nm}$, which is in agreement with a low-point symmetry around the europium(III) center. The emission is mainly from the ${ }^{5} \mathrm{D}_{0}$ level, but for compound 3 , some transitions from a higher energy ${ }^{5} \mathrm{D}_{1}$ level can also be observed in the spectral range from 520 to $570 \mathrm{~nm}$.

The ${ }^{5} \mathrm{D}_{0} \rightarrow{ }^{7} \mathrm{~F}_{0}$ transition is a reflection of the number of distinctive europium(III) bonding environments. For compound 1 , the ${ }^{5} \mathrm{D}_{0} \rightarrow{ }^{7} \mathrm{~F}_{0}$ transition is very weak at $\mathrm{RT}$ but becomes evident when the temperature is lowered to $77 \mathrm{~K}$, where one broad band with two amphibolous maxima is observed (see Figure S5 in the Supporting Information). Compound 3 only presents one single line for the ${ }^{5} \mathrm{D}_{0} \rightarrow{ }^{7} \mathrm{~F}_{0}$ transition at both RT and $77 \mathrm{~K}$ (Figure S6 in the Supporting Information). This result indicates that the two crystallographically independent europium(III) ions in compounds 1 and 3 have very similar or identical low-symmetry coordination environments, in agreement with the results of single-crystal Xray structural analyses. This is also reflected by the relatively high intensity ratio of ${ }^{5} \mathrm{D}_{0} \rightarrow{ }^{7} \mathrm{~F}_{2} /{ }^{5} \mathrm{D}_{0} \rightarrow{ }^{7} \mathrm{~F}_{1}$, which can be used to determine the symmetry and strength of the ligand field around europium(III). It is worth noting that this intensity ratio is highly temperature-dependent in the materials. For compound 1, it is high up to about 6.57 at $298 \mathrm{~K}$ but decreases to be about 1.61 at $77 \mathrm{~K}$. For compound 3, the corresponding values are found to be about 3.71 at $298 \mathrm{~K}$ and 1.57 at $77 \mathrm{~K}$, respectively. These values are much higher than the value (0.67) for a centrosymmetric europium(III) complex $^{25}$ but are typical for europium(III) in a low site symmetry without an inversion center. ${ }^{26}$ The broad ${ }^{5} \mathrm{D}_{0} \rightarrow{ }^{7} \mathrm{~F}_{0}$ transition and variable ${ }^{5} \mathrm{D}_{0} \rightarrow{ }^{7} \mathrm{~F}_{2} /{ }^{5} \mathrm{D}_{0} \rightarrow{ }^{7} \mathrm{~F}_{1}$ intensity ratio suggest flexible coordination environments around the europium(III) centers. The increasing trend of the asymmetry parameter with temperature indicates a stronger coupling between the DETACAP anions and europium(III), which can be expected at higher temperature. ${ }^{27}$ When the temperature is lowered to $77 \mathrm{~K}$, evident splitting and narrowing of the transitions was observed, indicating a stronger crystal field of the europium(III) bonding sites at low temperature.

The ${ }^{5} \mathrm{D}_{0}$ lifetimes of compounds 1 and 3 at RT and liquidnitrogen temperature were determined by monitoring the emission decay curves within the maximum of the ${ }^{5} \mathrm{D}_{0} \rightarrow{ }^{7} \mathrm{~F}_{2}$ transition and exciting at $393 \mathrm{~nm}$. The decay curves can best be fitted by single-exponential functions and yield lifetimes of 2.66 $\mathrm{ms}$ at $298 \mathrm{~K}$ and $2.74 \mathrm{~ms}$ at $77 \mathrm{~K}$ for compound 1 and $2.68 \mathrm{~ms}$ at $298 \mathrm{~K}$ and $3.14 \mathrm{~ms}$ at $77 \mathrm{~K}$ for compound 3, indicating that the ${ }^{5} \mathrm{D}_{0}$ lifetime is also temperature-dependent. Obviously, these values are much higher than those of many europiumcontaining polymers, confirming that in $\mathrm{IL} /$ soft materials the multiphonon relaxation processes can be reduced because of better shielding.

To have a better understanding of the radiative $\left(k_{\mathrm{r}}\right)$ and nonradiative $\left(k_{\mathrm{nr}}\right)$ pathways, the ${ }^{5} \mathrm{D}_{0}$ intrinsic quantum yield $\left(\Phi_{\mathrm{Ln}}\right)$ was estimated from the emission spectrum and lifetime of the ${ }^{5} \mathrm{D}_{0}$ state using eq $1^{28}$

$$
\Phi_{\mathrm{Ln}}=\frac{k_{\mathrm{r}}}{k_{\mathrm{r}}+k_{\mathrm{nr}}}=\frac{\tau_{\mathrm{obs}}}{\tau_{\mathrm{rad}}}
$$

where

$$
k_{\exp }=\tau_{\exp }^{-1}=k_{\mathrm{r}}+k_{\mathrm{nr}}
$$

$\tau_{\text {exp }}$ is the decay time obtained from the experimental decay curves. The radiative lifetime $\left(\tau_{\text {rad }}\right)$ can be calculated from eq 3 by assuming that the influence of the ${ }^{5} \mathrm{D}_{0}-{ }^{7} \mathrm{~F}_{5,6}$ transitions can be ignored and the energy of the ${ }^{5} \mathrm{D}_{0} \rightarrow{ }^{7} \mathrm{~F}_{1}$ transition (MD) and its oscillator strength are constant. ${ }^{29}$

$$
k_{\mathrm{r}}=\frac{1}{\tau_{\mathrm{rad}}}=A_{0 \rightarrow 1} \frac{\hbar \omega_{0 \rightarrow 1}}{S_{0 \rightarrow 1}} \sum_{J=0}^{4} \frac{S_{0-J}}{\hbar \omega_{0-J}}
$$

where $A_{0-1}$ is the Einstein coefficient of spontaneous emission between the ${ }^{5} \mathrm{D}_{0}$ and ${ }^{7} \mathrm{~F}_{1}$ Stark levels, usually considered to be 


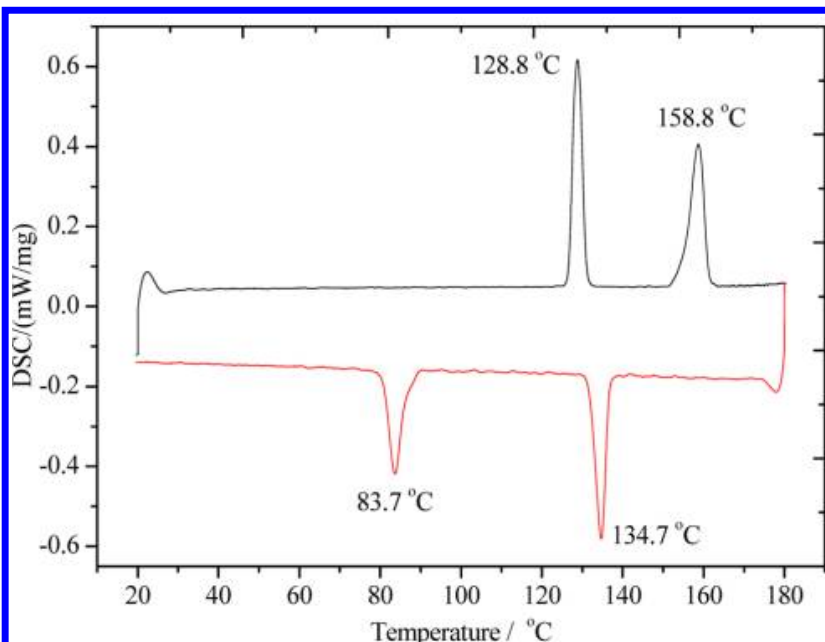

(a)

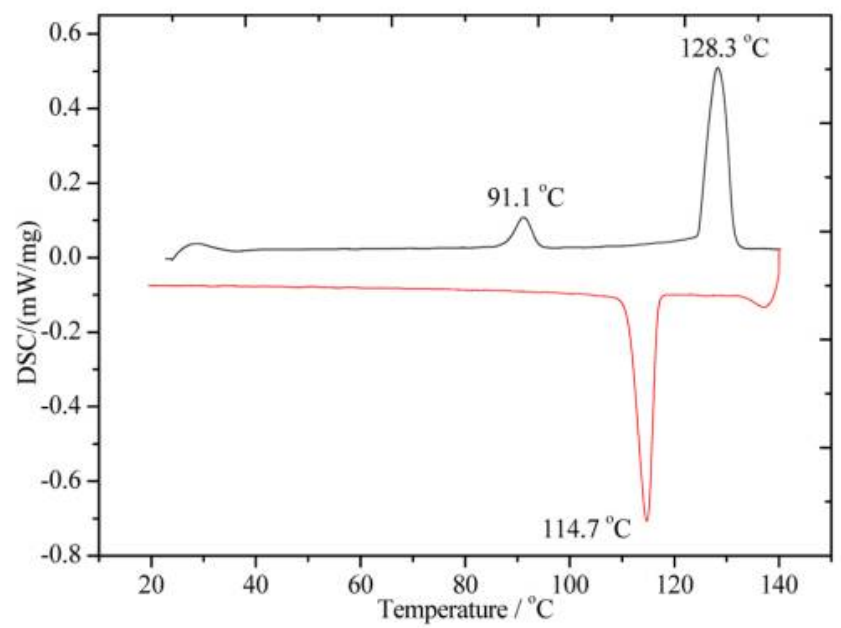

(c)

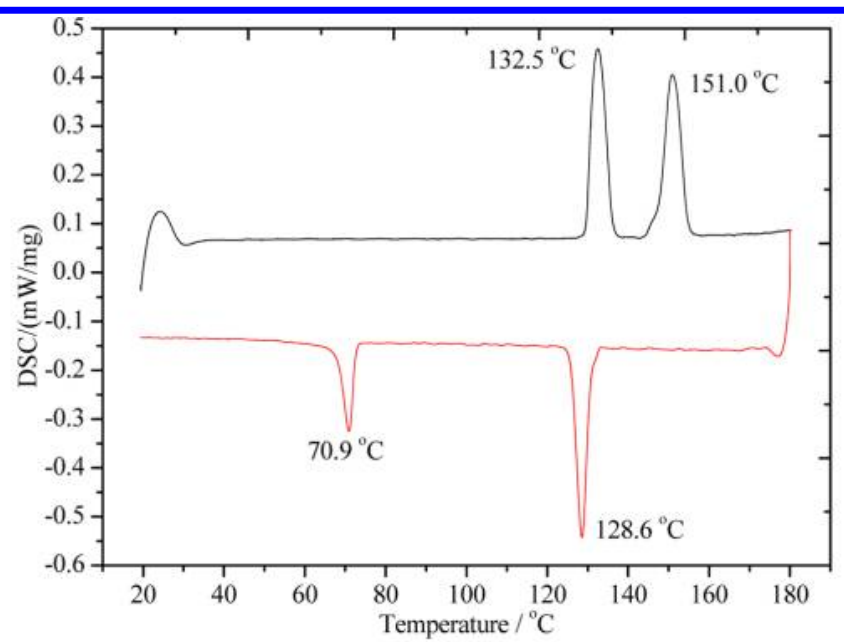

(b)

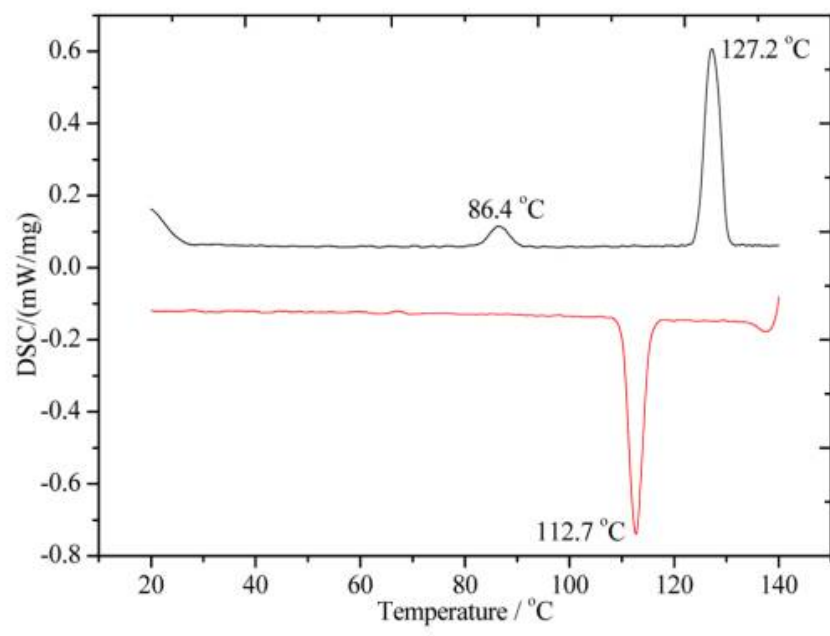

(d)

Figure 3. DSC diagrams of compounds 1-4.

Table 3. Important Vibrational Frequencies of Ligand HDETCAP and Compounds 1-4 and Their Assignments (Unit: $\mathrm{cm}^{-1}$ )

\begin{tabular}{|c|c|c|c|c|c|}
\hline \multirow[b]{2}{*}{ assignment } & \multicolumn{5}{|c|}{ compound } \\
\hline & HDETCAP & 1 & 2 & 3 & 4 \\
\hline$\nu(\mathrm{N}-\mathrm{H})$ & 3072.7 & & & & \\
\hline$\nu(\mathrm{C}=\mathrm{O})$ & 1743.8 & 1618.0 & 1618.2 & 1617.5 & 1617.7 \\
\hline$\nu(\mathrm{C}-\mathrm{N})$ & 1393.8 & 1363.1 & 1363.3 & 1362.4 & 1362.6 \\
\hline$\nu(\mathrm{P}=\mathrm{O})$ & 1264.6 & 1261.3 & 1262.2 & 1260.3 & 1263.2 \\
\hline$\nu_{\mathrm{as}}(\mathrm{C}-\mathrm{O})$ & 1166.9 & 1172.1 & 1171.9 & 1168.4 & 1167.6 \\
\hline$\nu_{\mathrm{as}}(\mathrm{P}-\mathrm{O})$ & 1030.7 & 1037.2 & 1037.2 & 1035.1 & 1035.2 \\
\hline$\nu_{\mathrm{as}}(\mathrm{P}-\mathrm{N})$ & 991.2 & 1010.6 & 1011.1 & 1009.8 & 1010.6 \\
\hline$\nu_{\mathrm{s}}(\mathrm{P}-\mathrm{O})$ & 964.3 & 968.0 & 968.0 & 970.4 & 970.6 \\
\hline$\nu(\mathrm{C}-\mathrm{Cl})$ & 674.8 & 675.9 & 675.4 & 677.0 & 677.1 \\
\hline
\end{tabular}

equal to $50 \mathrm{~s}^{-1} \cdot{ }^{30} \hbar \omega_{0-J}$ and $S_{0-J}$ are the energy and the integrated intensity of the ${ }^{5} \mathrm{D}_{0}-{ }^{7} \mathrm{~F}_{J}$ transitions, respectively.

The overall quantum yield $\left(\Phi_{\text {overall }}\right)$ for a lanthanide complex can be experimentally determined under excitation of the ligand. Given that the complex absorbs a photon, the overall quantum yield can be defined as eq $4 .^{31}$

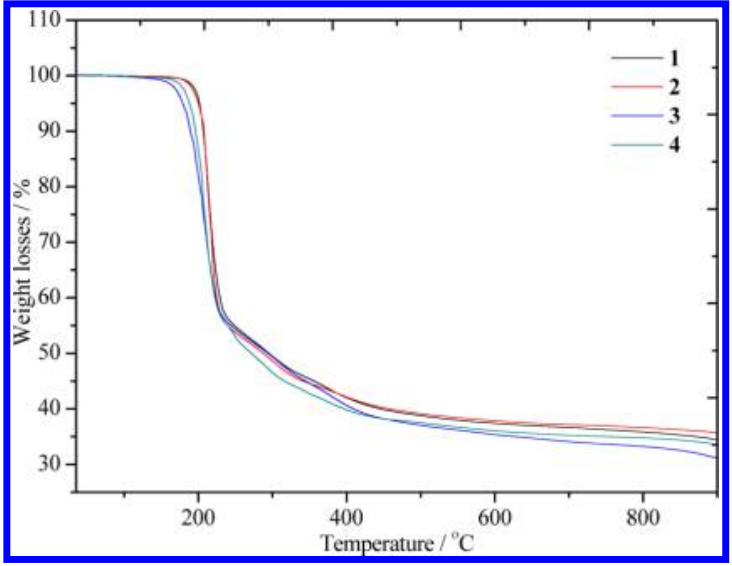

Figure 4. TGA curves of compounds 1-4.

$$
\Phi_{\text {sens }}=\frac{\Phi_{\text {overall }}}{\Phi_{\mathrm{Ln}}}
$$

Here, $\Phi_{\text {sens }}$ is the efficiency of energy transfer from the ligand to europium(3+) ions, and $\Phi_{\mathrm{Ln}}$ represents the intrinsic quantum 


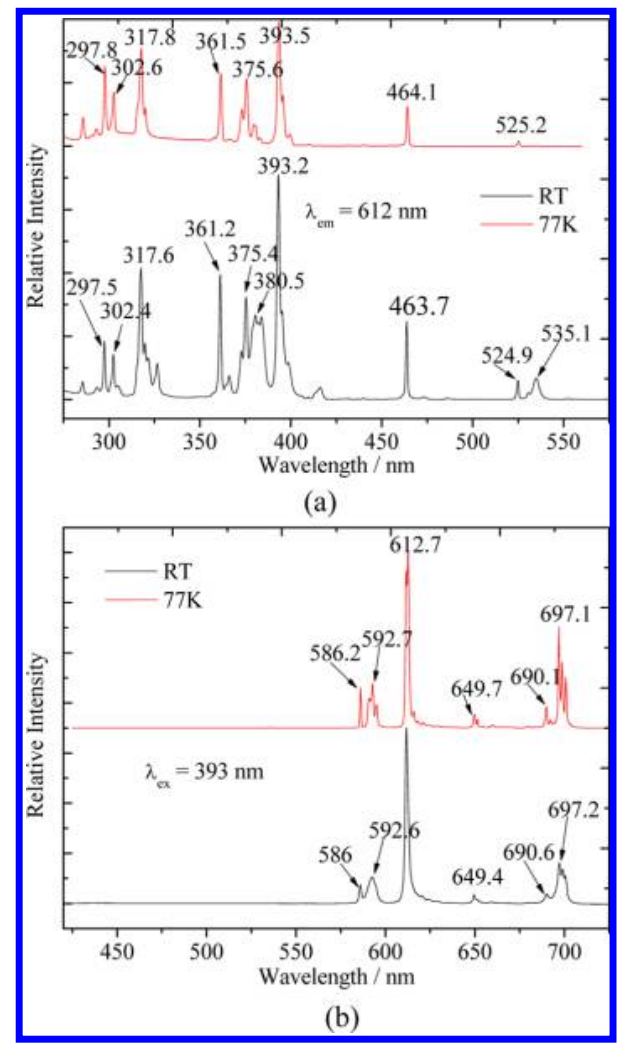

Figure 5. Excitation (a) and emission (b) spectra of compound $\mathbf{1}$.

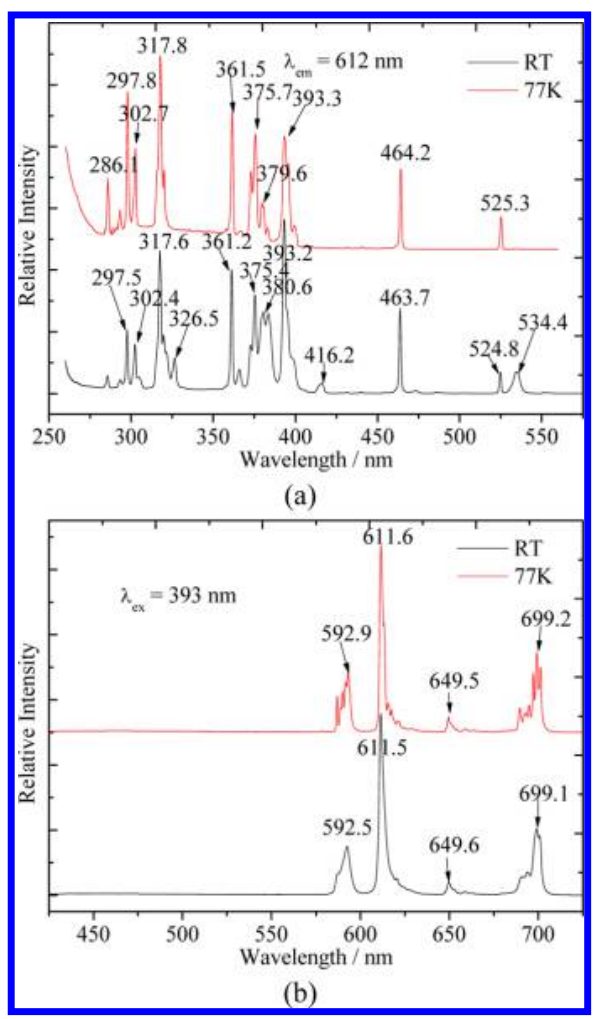

Figure 6. Excitation (a) and emission (b) spectra of compound 3.

yield of the lanthanide ion. The corresponding parameters of the photophysical properties for solid samples of $\mathbf{1}$ and $\mathbf{3}$ are summarized in Table 4 . It is noted that the quantum efficiencies of compounds $\mathbf{1}$ and $\mathbf{3}$ are very high and the nonradiative transition probabilities are even smaller than the radiative ones.

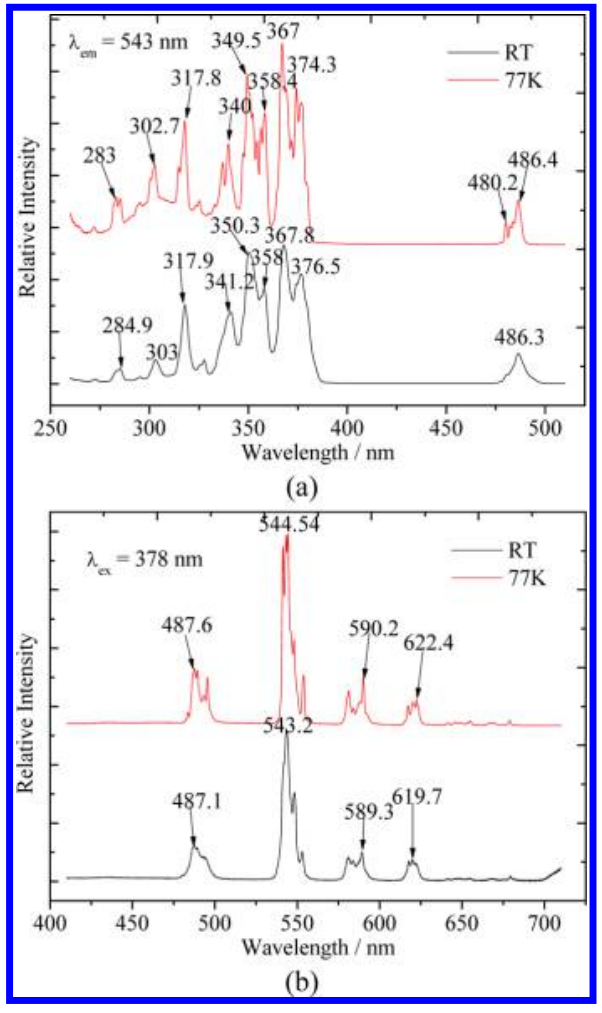

Figure 7. Excitation (a) and emission (b) spectra of compound 2.

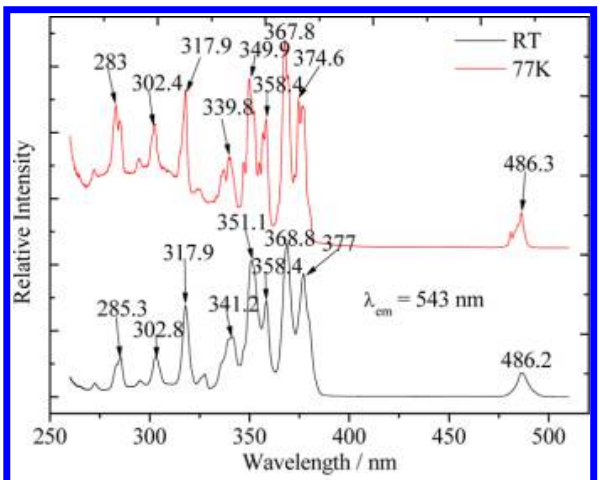

(a)

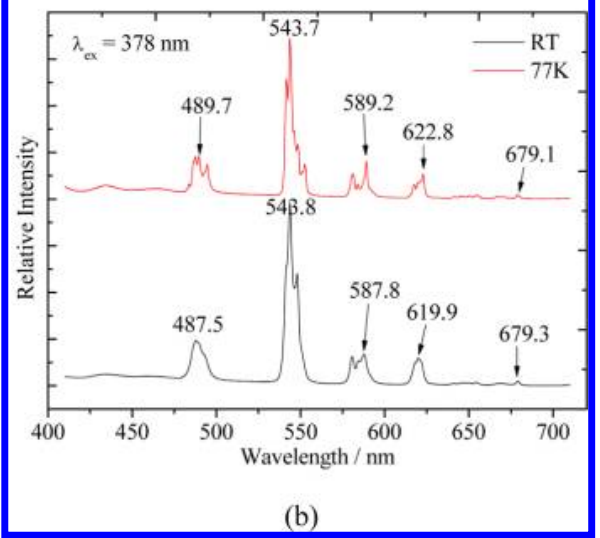

Figure 8. Excitation (a) and emission (b) spectra of compound 4.

This may be explained by the fact that there are no water molecules around the first coordination sphere of the europium(III) centers, which has been determined by the 
Table 4. Radiative $\left(k_{\mathrm{r}}\right)$ and Nonradiative $\left(k_{\mathrm{nr}}\right)$ Decay Rate, Observed Lifetime $\left(\boldsymbol{\tau}_{\mathrm{obs}}\right)$, Intrinsic Quantum Yield $\left(\boldsymbol{\Phi}_{\mathrm{Ln}}\right)$, Efficiency of Energy Transfer $\left(\boldsymbol{\Phi}_{\text {sens }}\right)$, and Overall Quantum Yield $\left(\Phi_{\text {overall }}\right)$ for Compounds 1 and 3 and Some Selected Lanthanide $\beta$ Diketonates at RT

\begin{tabular}{|c|c|c|c|c|c|c|}
\hline compound & $k_{\mathrm{r}}\left(\mathrm{ms}^{-1}\right)$ & $k_{\mathrm{nr}}\left(\mathrm{ms}^{-1}\right)$ & $\tau_{\text {obs }}(\mathrm{ms})$ & $\Phi_{\text {Ln }}(\%)$ & $\Phi_{\text {sens }}(\%)$ & $\Phi_{\text {overall }}(\%)$ \\
\hline$\left[\mathrm{C}_{2} \operatorname{mim}\right]\left[\mathrm{Eu}(\mathrm{DETCAP})_{4}\right](\mathbf{1})$ & 0.285 & 0.092 & 2.66 & 76 & 40 & 30 \\
\hline$\left[\mathrm{C}_{4} \operatorname{mim}\right]\left[\mathrm{Eu}(\mathrm{DETCAP})_{4}\right]$ & 0.281 & 0.048 & 2.68 & 75 & 65 & 49 \\
\hline $\mathrm{Eu}(\mathrm{TFI})_{3}(\mathrm{bpy})^{32}$ & 2.16 & 9.708 & 0.084 & 18 & 74 & 13.5 \\
\hline $\mathrm{Eu}(\mathrm{TFI})_{3}(\mathrm{phen})^{32}$ & 1.92 & 5.884 & 0.128 & 25 & 76 & 18.6 \\
\hline $\mathrm{Eu}(\mathrm{PFNP})_{3}(\text { phen })^{33}$ & 0.591 & 0.255 & 1.183 & 70 & 53 & 37 \\
\hline $\mathrm{Eu}(\mathrm{PBI})(\mathrm{bpy})^{34}$ & 6.911 & 3.314 & 0.978 & 68 & 22 & 15 \\
\hline $\mathrm{Eu}(\mathrm{TTA})_{3}(\mathrm{phen})^{35}$ & 0.713 & 0.695 & 0.71 & 51 & 95 & 48 \\
\hline $\mathrm{Eu}(\mathrm{Br}-\mathrm{TTA})_{3}(\mathrm{phen})^{36}$ & 0.729 & 1.271 & 0.5 & 36 & 100 & 37 \\
\hline $\mathrm{Eu}(\mathrm{CPFHP})_{3}(\mathrm{DDXPO})^{36}$ & 0.986 & 0.413 & 0.714 & 70 & 66 & 47 \\
\hline $\mathrm{Eu}_{2}(\mathrm{BTP})_{3}(\mathrm{phen})_{2}^{37}$ & 0.857 & 0.246 & 0.906 & 78 & 83 & 65 \\
\hline
\end{tabular}

single-crystal X-ray analyses. The absence of coordinated water molecules can be further evidenced by the empirical formula of Supkowski and Horrocks: ${ }^{38}$

$$
n_{\mathrm{w}}=1.11\left(k_{\exp }-k_{\mathrm{r}}-0.31\right)
$$

For compounds $\mathbf{1}$ and $\mathbf{3}$, the calculated number of water molecules $\left(n_{\mathrm{w}}\right)$ are meaningless negative values, in agreement with the crystallographic results that indicate no aqua ligands coordinate to the europium(III) centers.

Compared with other recent reported europium(III) $\beta$ diketonate complexes, it is clear that compounds $\mathbf{1}$ and $\mathbf{3}$ have the smallest radiative $\left(k_{\mathrm{r}}\right)$ and nonradiative $\left(k_{\mathrm{nr}}\right)$ decay rates, the highest intrinsic quantum yields $\left(\Phi_{\mathrm{Ln}}\right)$, and the longest decay times $\left(\tau_{\text {rad }}\right)$. The overall luminescence quantum yields $\left(\Phi_{\text {overall }}\right)$ and energy-transfer efficiencies $\left(\Phi_{\text {sens }}\right)$ observed for $\mathbf{1}$ and 3 are modest (Table 4). The low energy-transfer efficiency values and radiative decay rates of $\mathbf{1}$ and 3 indicate that the $\beta$ diketonate ligand DETCAP is a less effective sensitizer compared with the aromatic ones, but in $\mathbf{1}$ and 3, the europium centers are well-shielded from $\mathrm{N}-\mathrm{H}$ or $\mathrm{O}-\mathrm{H}$ high-energy oscillators and well-separated from each other, reducing the probability of noradiative energy loss and enhancing the emission intensity and decay times.

Compounds $\mathbf{2}$ and $\mathbf{4}$ are terbium-containing salts, which are of great interest because they are efficient emitters of green light. The excitation and emission spectra of 2 and 4 measured at 298 and $77 \mathrm{~K}$ are shown in Figures 7 and 8. Obviously, these two salts show very similar excitation and emission spectra. The excitation spectra obtained by monitoring at $543 \mathrm{~nm}$ are composed of one series of bands at about 272, 285, 295, 303, $318,327,341,350,358,368,377$, and $486 \mathrm{~nm}$, corresponding to the electronic transitions of terbium $(3+)$ ions from the ground state ${ }^{7} \mathrm{~F}_{6}$ to the excited state ${ }^{5} \mathrm{D}_{0},{ }^{5} \mathrm{G}_{2-6},{ }^{5} \mathrm{~L}_{10}$, and ${ }^{5} \mathrm{D}_{2-4}$ intraconfigurationally forbidden $4 \mathrm{f}^{8} \rightarrow 4 \mathrm{f}^{8}$ transitions. Under excitation of $378 \mathrm{~nm}$ light, one set of bands around 487, 543, $589,620,654,669$, and $679 \mathrm{~nm}$, corresponding to the characteristic ${ }^{5} \mathrm{D}_{4} \rightarrow{ }^{7} \mathrm{~F}_{J}(J=6,5,4,3,2,1,0)$ transitions of the terbium(III) ion, can be detected with the ${ }^{5} \mathrm{D}_{4} \rightarrow{ }^{7} \mathrm{~F}_{5}$ green emission as the strongest. It is noticed that the decreasing of temperature from 298 to $77 \mathrm{~K}$ leads to the further splitting of the bands but has a very small effect on the narrowing of the respective transitions. Their decay times $\left({ }^{5} \mathrm{D}_{4}\right)$ are also not that temperature-dependent. By monitoring at $543 \mathrm{~nm}$ and excitation at $378 \mathrm{~nm}$, the respective lifetimes are determined to be $2.74 \mathrm{~ms}(298 \mathrm{~K})$ and $2.43 \mathrm{~ms}(77 \mathrm{~K})$ for 2 and $2.60 \mathrm{~ms}$ $(298 \mathrm{~K})$ and $2.61 \mathrm{~ms}(77 \mathrm{~K})$ for 4 . These suggest that the emission of terbium(III) is insensitive to the changing environment. The RT emission quantum yields of $\mathbf{2}$ and 4 were determined to be 37 and $39 \%$.

\section{CONCLUSION}

In summary, one series of lanthanide-containing soft materials have been synthesized from imidazolium-based ILs and DETCAP. These salts are thoroughly characterized using IR, EA, DSC, TGA, powder and single-crystal XRD, and photophysical methods. The single-crystal structural analyses indicate that these salts have the characteristic [cation][Ln(anion) $)_{4}$ component in which the lanthanide centers are chelated by four DETCAP anions, forming complex anions, and interact with the imidazolium countercations with $\mathrm{C}-\mathrm{H} \cdots$ $\mathrm{O}$ hydrogen bonds. The respective lanthanide centers are wellshielded by the diester chelators. No water or other solvent molecule is found in the structure. The similarity of these salts on structure leads to similar thermal stability so that they are stable up to 160 or $180{ }^{\circ} \mathrm{C}$ and start to decompose upon further heating. Their melting points are all above $120{ }^{\circ} \mathrm{C}$ but can be deduced by elongating the length of the alkyl side chain of the imidazolium cation. Solid-to-solid phase transition occurs during the heating or cooling process or both. As expected, these lanthanide-containing salts are highly luminescent and display their characteristic $\mathrm{f}-\mathrm{f}$ transitions with decay times above $2 \mathrm{~ms}$ and quantum yields in the range of 30-49\%. Their outstanding photophysical properties inspire us to further investigate lanthanide-containing ILs or soft materials.

\section{ASSOCIATED CONTENT}

\section{S Supporting Information}

$\mathrm{XRD}, \mathrm{C}-\mathrm{H} \cdots \mathrm{O}$ bonds, ${ }^{5} \mathrm{D}_{0}-{ }^{7} \mathrm{~F}_{0}$ transitions of compounds 1 and 3, and X-ray crystallographic files for 1-4 in CIF format. This material is available free of charge via the Internet at http://pubs.acs.org.

\section{AUTHOR INFORMATION}

\section{Corresponding Authors}

*E-mail: tangsf@qibebt.ac.cn.

*E-mail: mudring@iastate.edu or anja.mudring@rub.de.

\section{Notes}

The authors declare no competing financial interest.

\section{ACKNOWLEDGMENTS}

This work was supported by the National Natural Science Foundation of China (Grant 21171173). 


\section{REFERENCES}

(1) (a) Seddon, K. R. I. Chem. Technol. Biotechnol. 1997, 68, 351356. (b) Seddon, K. R. Kinet. Catal. 1996, 37, 693-697. (c) Earle, M. J.; Seddon, K. R. Pure Appl. Chem. 2000, 72, 1391-1398. (d) Welton, T. Chem. Rev. 1999, 99, 2071-2084. (e) Wasserscheid, P.; Keim, W. Angew. Chem. 2000, 112, 3926-3945; Angew. Chem., Int. Ed. 2000, 39, 3772-3789. (f) Wasserscheid, P.; Welton, T. Ionic Liquids in Synthesis; Wiley-VCH: Weinheim, Germany, 2003.

(2) (a) Anderson, J. L.; Ding, J.; Welton, T.; Armstrong, D. W. I.Am. Chem. Soc. 2002, 124, 14247-14254. (b) Znamenskiy, V.; Kobrak, M. N. I. Phvs. Chem. B 2004, 108, 1072-1079. (c) Dzyuba, S. V.; Bartsch, R. A. Tetrahedron Lett. 2002, 43, 4657-4659. (d) Aki, S. N. V. K.; Brennecke, J. F.; Samanta, A. Chem. Commun. 2001, 413-414. (e) Carmichael, A. J.; Seddon, K. R. I. Phvs. Org. Chem. 2000, 13, 591595. (f) Deetlefs, M.; Seddon, K. R. Green Chem. 2010, 12, 17-30.

(3) (a) Peppel, T.; Köckerling, M.; Geppert-Rybczyńska, M.; Ralys, R. V.; Lehmann, J. K.; Verevkin, S. P.; Heintz, A. Angew. Chem. Int. Ed. 2010, 49, 7116-7119. (b) Funasako, Y.; Inagaki, T.; Mochida, T.; Sakurai, T.; Ohta, H.; Furukawa, K.; Nakamura, T. Dalton Trans. 2013, 42, 8317-8327. (c) Brown, P.; Butts, C. P.; Eastoe, J.; Padrón Hernández, E.; Luis de Araujo Machado, F.; de Oliveira, R. I. Chem. Commun. 2013, 49, 2765-2767. (d) Bäcker, T.; Breunig, O.; Valldor, M.; Merz, K.; Vasylyeva, V.; Mudring, A.-V. Crust. Growth Des. 2011, $11,2564-2571$.

(4) (a) Mallick, B.; Balke, B.; Felser, C.; Mudring, A.-V. Angew. Chem. 2008, 120, 7747-7750; Angew. Chem., Int. Ed. 2008, 47, 7635-7638. (b) Gago, S.; Cabrita, L.; Carlos Lima, J.; Branco, L. C.; Pina, F. Dalton Trans. 2013, 42, 6213-6218. (c) Tanabe, K.; Suzui, Y.; Hasegawa, M.; Kato, T. I. Am. Chem. Soc. 2012, 134, 5652-5661.

(5) (a) Getsis, A.; Balke, B.; Felser, C.; Mudring, A.-V. Cryst. Growth. Des. 2009, 9, 4429-4437. (b) Goossens, K.; Nockemann, P.; Driesen, K.; Goderis, B.; Görller-Walrand, C.; Van Hecke, K.; Van Meervelt, L.; Pouzet, E.; Binnemans, K.; Cardinaels, T. Chem. Mater. 2008, 20, 157-168. (c) Ji, S.-P.; Tang, M.; He, L.; Tao, G.-H. Chem.-Eur.I. 2013, 19, 4452-4461.

(6) Mudring, A.-V.; Tang, S.-F. Eur. I. Inorg. Chem. 2010, 25692581.

(7) (a) Han, Y.; Lin, C.; Meng, Q.; Dai, F.; Sykes, A. G.; Berry, M. T. P.; May, S. Inorg. Chem. 2014, 53, 5494-5501. (b) Borges, A. S.; Dutra, J. D. L.; Freire, R. O.; Moura, R. T., Jr.; Da Silva, J. G.; Malta, O. L.; Araujo, M. H.; Brito, H. F. Inorg. Chem. 2012, 51, 12867-12878. (c) Mei, Y.; Lu, Y.; Yan, B. I. Photochem. Photobiol. A: Chem. 2014, 280, 1-4. (d) Yan, B. Inorg. Chem. Commun. 2014, 40, 39-42.

(8) (a) Driesen, K.; Nockemann, P.; Binnemans, K. Chem. Phys. Lett. 2004, 395, 306-310. (b) Mudring, A.-V.; Babai, A.; Arenz, S.; Giernoth, R.; Binnemans, K.; Driesen, K.; Nockemann, P. I. Allovs Compd. 2006, 418, 204-208. (c) Brandner, A.; Kitahara, T.; Beare, N.; Lin, C.; Berry, M. T.; May, P. S. Inorg. Chem. 2011, 50, 6509-6520.

(9) Nockemann, P.; Beurer, E.; Driesen, K.; Van Deun, R.; Van Hecke, K.; Van Meervelt, L.; Binnemans, K. Chem. Commun. 2005, 4354-4356.

(10) Nockemann, P.; Thijs, B.; Lunstroot, K.; Parac-Vogt, T. N.; Görller-Walrand, C.; Binnemans, K.; Van Hecke, K.; Van Meervelt, L.; Nikitenko, S.; Daniels, J.; Hennig, C.; Van Deun, R. Chem.-Eur. I. 2009, 15, 1449-1461.

(11) (a) Babai, A.; Mudring, A.-V. Inorg. Chem. 2005, 44, 81688169. (b) Babai, A.; Mudring, A.-V. Chem. Mater. 2005, 17, 62306238. (c) Babai, A.; Mudring, A.-V. Inorg. Chem. 2006, 45, 4874-4876. (12) (a) Babai, A.; Pitula, S.; Mudring, A.-V. Eur. I. Inorg. Chem. 2010, 4933-4937. (b) Babai, A.; Mudring, A.-V. Z. Anorg. Allg. Chem. 2008, 634, 938-940.

(13) Tang, S.-F.; Babai, A.; Mudring, A.-V. Angew. Chem. 2008, 120, 7743-7746; Angew. Chem., Int. Ed. 2008, 47, 7631-7634.

(14) Tang, S.-F.; Mudring, A.-V. Eur. J. Inorg. Chem. 2009, 27692775 .

(15) Binnemans, K. Rare Earth Beta-Diketonates. Handbook on the Physics and Chemistry of Rare Earths; Gschneidner, K. A., Jr., Bünzli, J. -C. G., Pecharsky, V. K., Eds.; Elsevier BV: Amsterdam, The Netherlands, 2005; Vol. 35, Chapter 225, pp 107-272.
(16) (a) Kiersanov, A. V.; Derkatch, G. I. Zh. Org. Khim. 1956, 26, 2631. (b) Gubina, K. E.; Shatrava, J. A.; Ovchynnikov, V. A.; Amirkhanov, V. M. Polvhedron 2000, 19, 2203-2209. (c) Iriarte, A. G.; Erben, M. F.; Gholivand, K.; Jios, J. L.; Ulic, S. E.; Védova, C. O. D. I. Mol. Struct. 2008, 886, 66-71. (d) Borzechowska, M.; Trush, V.; Turowska-Tyrk, I.; Amirkhanov, W.; Legendziewicz, J. I. Allovs Compd. 2002, 341, 98-106.

(17) Baek, S.; Kim, Y. H.; Eom, Y. K.; Oh, J. H.; Kim, H. K.; Aebischer, A.; Gumy, F.; Chauvin, A.-S.; Bünzli, J.-C. G. Dalton Trans. 2010, 39, 1532-1538.

(18) (a) Dieke, G. H. Spectra and energy levels of rare earth ions in crystals; Interscience Publishers: New York, 1968. (b) Carnall, W. T.; Crosswhite, H. M.; Crosswhite, H. Energy level structure and transition probabilities in the spectra of trivalent lanthanides in $\mathrm{LaF}_{3}$. Special Report; Chemistry Division, Argonne National Laboratory: Argonne, IL, 1977.

(19) SAINT, version 6.45; Bruker Analytical X-ray Systems Inc.: Madison, WI, 2003.

(20) Sheldrick, G. M. SADABS, version 2.10; Bruker AXS Inc.: Madison, WI, 2003.

(21) Sheldrick, G. M. SHELXS-97, Program for Crystal Structure Solution and Refinement; University of Göttingen: Göttingen, Germany, 1997.

(22) Sheldrick, G. M. SHELXTL, Crystallographic Software Package, version 5.1; Bruker AXS Inc.: Madison, WI, 1998.

(23) Glover, P. B.; Bassett, A. P.; Nockemann, P.; Kariuki, B. M.; Van Deun, R; Pikramenou, Z. Chem.-Eur. I. 2007, 13, 6308-6320.

(24) Trush, V. A.; Swiatek-Kozlowska, J.; Skopenko, V. V.; Amyrkhanov, V. M. Z. Naturforsch. 2001, 56b, 249-254.

(25) Klink, S. I.; Grave, L.; Reinhoudt, D. N.; van Veggel, F. C. J. M.; Werts, M. H. V.; Geurts, F. A. J.; Hofstraat, J. W. J. Phys. Chem. A 2000, 104, 5457-5468.

(26) (a) Fu, L. S.; Sá Ferreira, R. A.; Silva, N. J. O.; Fernandes, A. J.; Ribeiro-Claro, P.; Gonçalves, I. S.; de Zea Bermudez, V.; Carlos, L. D. I. Mater. Chem. 2005, 15, 3117-3125. (b) Binnemans, K.; Lenaerts, P.; Driesen, K.; Görller-Walrand, C. L. Mater. Chem. 2004, 14, 191-195.

(27) (a) Getsis, A.; Mudring, A.-V. Crust. Res. Technol. 2008, 43, 1187-1196. (b) Tang, S.-F.; Cybinska, J.; Mudring, A.-V. Helv. Chim. Acta 2009, 92, 2375-2386.

(28) (a) Chauvin, A.-S.; Gumy, F.; Imbert, D.; Bünzli, J.-C. G. Spectrosc. Lett. 2004, 37, 517-532. (b) Chauvin, A.-S.; Gumy, F.; Imbert, D.; Bünzli, J.-C. G. Spectrosc. Lett. 2007, 40, 193-193.

(29) Viswanathan, S.; Bettenacourt-Dias, A. D. Inorg. Chem. 2006, 45, 10138-10146.

(30) (a) Carlos, L. D.; Messaddeq, Y.; Brito, H. F.; Sá Ferreira, R. A.; de Zea Bermudez, V.; Ribeiro, S. J. L. Adv. Mater. 2000, 12, 594-598. (b) Sá Ferreira, R. A.; Carlos, L. D.; Gonçalves, R. R.; Ribeiro, S. J. L.; de Zea Bermudez, V. Chem. Mater. 2001, 13, 2991-2998. (c) Fernandes, M.; de Zea Bermudez, V.; Sá Ferreira, R. A.; Carlos, L. D.; Charas, A.; Morgado, J.; Silva, M. M.; Smith, M. I. Chem. Mater. 2007, 19, 3892-3901. (d) Werts, M. H. V.; Jukes, R. T. F.; Verhoeven, J. W. Phvs. Chem. Chem. Phvs. 2002, 4, 1542-1548.

(31) Xiao, M.; Selvin, P. I. Am. Chem. Soc. 2001, 123, 7067-7073.

(32) Li, J.; Li, H.; Yan, P.; Chen, P.; Hou, G.; Li, G. Inorg. Chem. 2012, 51, 5050-5057.

(33) Raj, D. B. A.; Bijiu, S.; Reddy, M. L. P. Inorg. Chem. 2008, 47, $8091-8100$

(34) Biju, S.; Raj, D. B. A.; Reddy, M. L. P.; Kariuki, B. M. Inorg. Chem. 2006, 45, 10651-10660.

(35) Freund, C.; Porzio, W.; Giovanella, U.; Vignali, F.; Pasini, M.; Destri, S. Inorg. Chem. 2011, 50, 5417-5429.

(36) Raj, D. B. A.; Francis, B.; Reddy, M. L. P.; Butorac, R. R.; Lynch, V. M.; Cowley, A. H. Inorg. Chem. 2010, 49, 9055-9063.

(37) Shi, J.; Hou, Y.; Chu, W.; Shi, X.; Gu, H.; Wang, B.; Sun, Z. Inorg. Chem. 2013, 52, 5013-5022.

(38) (a) Supkowski, R. M.; Horrocks, W. W. Inorg. Chim. Acta 2002, 340, 44-48. (b) Liu, F.-Y.; Roces, L.; Sá Ferreira, R. A.; GarcíaGranda, S.; García, J. R.; Carlos, L. D.; Rocha, J. L. Mater. Chem. 2007, 17, 3696-3701. 